$\mathbb{P}$ periodica polytechnica

Civil Engineering

58/4 (2014) 431444

doi: $10.3311 /$ PPci.2113

http://periodicapolytechnica.org/ci

Creative Commons Attribution (1)

\section{Rising damp analysis and selection of optimal handling method in masonry construction}

\author{
Norbert Harmati / Željko Jakšić / Milan Trivunić / Vesna Milovanović
}

Received 2013-05-15, revised 2014-04-08, accepted 2014-07-07

\begin{abstract}
Masonry construction of architectural heritage is exposed to vertical rising damp process due to inappropriate waterproofing by causing decay and deterioration in porous construction materials. Numerous researches have been devoted in order to find an optimal remedial method for rising damp prevention. For this research in-situ monitoring and laboratory testing were performed in order to analyze the rising damp and masonry units' quality and in a specific building. The testing of physical and mechanical properties of specimens was done according to the standard.

This paper presents a methodical approach for selecting an optimal handling method for rising damp prevention in masonry construction. The selection was performed among the most disseminated rising damp prevention techniques used in engineering practice. The procedure of appropriate damp handling is demonstrated according to the effectiveness, duration and economic aspects of the solution in comparison with recent studies. The main purpose of the analysis is to optimize rising damp handling in masonry construction for conserving architectural heritage of great value.
\end{abstract}

\section{Keywords}

Masonry construction · rising damp · optimal handling method $\cdot$ handling selection

\section{Norbert Harmati}

University of Novi Sad, Faculty of Technical Sciences, Department of Civil Engineering and Geodesy, Trg Dositeja Obradovic 6, 21000 Novi Sad, Republic of Serbia

e-mail: norbert.harmati@gmail.com

\section{Željko Jakšić}

Milan Trivunić

\section{Vesna Milovanović}

University of Novi Sad, Faculty of Technical Sciences, Department of Civil Engineering and Geodesy, Trg Dositeja Obradovic 6, 21000 Novi Sad, Republic of Serbia

\section{Introduction}

Masonry construction of architectural heritage is exposed to decay and deterioration due to severe environmental conditions that threaten its stability during the exploitation period. Masonry construction is a bearing structural system, which due to its own weight carries the forces of the whole building structure. In a wider range this composite construction is exposed to various forces, vertical loads of the ceiling and roof construction and horizontal forces caused by the wind, seismic forces and ground pressure on the basement walls. The main characteristics of the $19^{\text {th }}$ century architecture in the Austro-Hungarian Empire are massive masonry structures which were used in constructing public buildings of monumental and moderate architectural style.

The selected building is exposed to rising damp which led to decay of masonry units in the basement walls since appropriate waterproofing was not provided during the construction of the building in 1892. This paper presents a methodical selection of an optimal remedial method. The selection was performed among the most disseminated rising damp prevention techniques used in engineering practice. The procedure of appropriate waterproofing is demonstrated according to the effectiveness, duration and economic aspects of the solution in comparison with recent studies. Research efforts have been devoted in proper elimination of rising damp in masonry construction [1--3]. The optimization of the remedial method varies from construction type and material. In this case optimization is performed from the evaluation of the efficiency among the selected handling methods.

The rising damp handling method is performed on a public building situated in the city of Zrenjanin (Nagybecskerek), Vojvodina Province, Serbia. The structural failure observed for buildings built at the end of the $19^{\text {th }}$ century on this territory is due to high groundwater level, soil structure and capillary absorption in the porous construction units and mortar, since waterproofing was not provided at that time in the construction techniques.

The paper consists of three chapters which explain the following processes: 
- vertical rising damp analysis and the effect of salt crystallization in building materials,

- laboratory testing for determination of material quality by measuring the density, water absorption and compressive strength,

- selection of optimal handling method for the specified building,

- construction phases of the selected handling method with the restoration of the architectural motives on the destructed segments.

\section{A brief description of the construction period and ar- chitectural style of the building}

One of the pearls of architectural heritage on the territory of Vojvodina is the former Merchant Academy, built in 1892 by the plans of Istvan Kis, Fig. 1 today High School of Electrical and Civil Engineering, Fig. 2 [4]. Public projects had to ensure an undoubted rise of the $19^{\text {th }}$ century former city of Nagybecskerek, to provide it with a considerable prestige cultural environment, while in the urban context its striking angular position makes a significant mark in the formation of the spatial layout of the Kalvin square, the most successful artistically built environment in the old town. The formation of stylistic expression of the building was inspired by the reminiscences of the Italian Renaissance architecture [5]. The interest in the Italian Renaissance significantly increased when in 1860 Burkhart published his study "The Culture of the Renaissance in Italy", leading to the aim that Renaissance in some countries has become a national style [6]. The buildings monumental form is combined with moderate decoration of floral motives, symbolic for the period of secession in the second half of the $19^{\text {th }}$ century.

\section{Vertical rising damp analysis and the effect of salt crystallization in building materials}

\subsection{Capillary forces and height of damp rising}

The term rising damp confirms to the vertical upward movement of the materials capillary absorption of water. The concentrated moisture in the lower part of the construction causes decay and deterioration in the building material of archeological heritage [7]. Water has strong affinity with the capillaries in the material structure which leads to the rising damp process through capillarity [8]. Capillary forces are primary physical processes which are responsible for the rise of liquid in the pores of materials. These forces are responsible for the initial uptake of water from external sources such as ground water, rain or leaks and condensation. Capillarity is also the cause of migration within the material, the redistribution of water from place to place which is associated usually with the local differences of water content. Eventually, water may leave the structure and the only important means to do this is by evaporation. The liquid vapor phase change may occur at the wall surface or inside the porous material, followed by vapor migration within the material. These various processes all fall within the scientific theory of unsaturated flow, the term emphasizing that the materials in the building fabric are rarely fully saturated [7].

The boundary between wet and dry region within the material depend on the porosity of the material. The order of altitude is calculated with the Eq. (1) [9]:

$$
\delta u=u_{a}-u_{w}
$$

where $\delta u$ refers to the pressure difference of air $U_{a}$ and water $u_{w}$. This process is known as suction. In the case of twodimensional curved surfaces, the equilibrium condition in the vertical direction is satisfied when, Eq. (2):

$$
\delta u=\frac{T_{s}}{R}
$$

where $T_{S}$ is the tension force per unit length of membrane. In the case of three-dimensional curved surface, the equilibrium condition is expressed with Laplace's rule in Eq. (3):

$$
\delta u=T_{s}\left(\frac{1}{R_{1}}+\frac{1}{R_{2}}\right)
$$

where $R_{1}$ and $R_{2}$ are the major radiuses of the membrane. The size of the surface tension in the water with the air on the border boundary depends of the temperature. On the temperature between $0^{\circ} \mathrm{C}$ and $30^{\circ} \mathrm{C}$ the size of the surface tension ranges from $75.7 \times 10^{-3} \mathrm{~N} / \mathrm{m}$ to $71.2 \times 10^{-3} \mathrm{~N} / \mathrm{m}$. For the usual temperature of $20^{\circ} \mathrm{C}$ the tension force is around $72.8 \times 10^{-3} \mathrm{~N} / \mathrm{m}$.

The height of the capillary rise can be measured by using capillary tubes with various diameters. The existence of surface tension lowers the pressure in the liquid immediately below the surface defined by $h_{c} \gamma_{w}$ where $h_{c}$ is the height of capillary rise, and $\gamma_{w}$ is constant, $9.807 \mathrm{kN} / \mathrm{m}^{2}$. The liquid molecules are exposed to lower atmospheric pressure on the height $h_{c}$ than on level 0 where $h_{c}=0$, so the equation can be written $\delta u=h_{c} \gamma_{w}$. The absolute pressure in the liquid can even be negative which implies that the liquid is exposed to tension. The diameter of the tube is adjusted to the pore dimension of a characteristic material. The measured heights are classified according to the materials in Table 1 [9].

Tab. 1. Average height of capillary rising and tension in various material types

\begin{tabular}{ccc}
\hline Material & Height $h_{c}[\mathrm{~m}]$ & Tension $\left[\mathrm{kN} / \mathrm{m}^{2}\right]$ \\
\hline Gravel & $h_{c}<0.05$ & $<0.05$ \\
Sand & $0.05-1$ & $0.5-10$ \\
Dust & $1-10$ & $10-100$ \\
Clay & $h_{c}>10$ & $>100$ \\
\hline
\end{tabular}

The soil structure of the analyzed area is clay, while the importance lies in the exposition to saturation. Groundwater level on this territory varies from $-3 \mathrm{~m}$ to $-1 \mathrm{~m}$ respectively. The height of the rising damp will be measured in the masonry structure. 


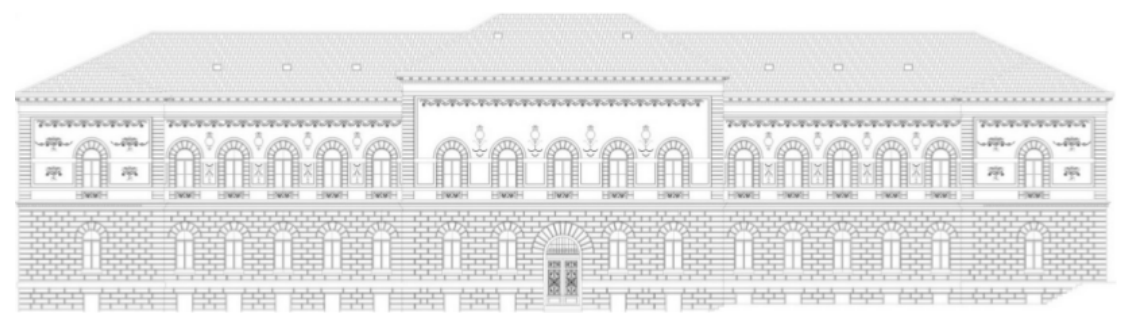

Fig. 1. Southern elevation

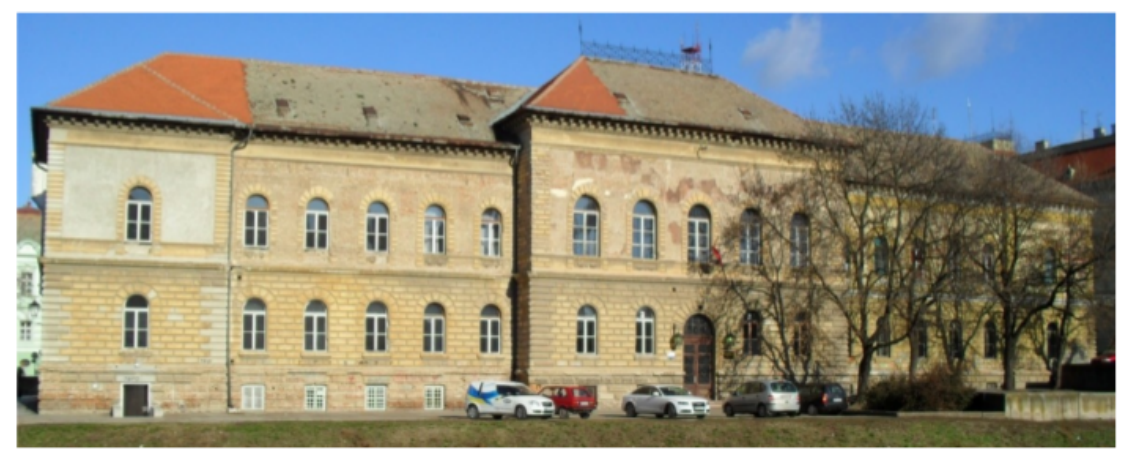

Fig. 2. High School of Electrical and Civil Engineering

\subsection{Vertical water distribution in masonry construction}

Series of complex equations describe the flow processes through the porous structure which form equilibrium with evaporation [10]. The height of rise is governed by the factors relating to capillary pores, wall thickness and evaporation rate [1.2. 11]. In principle, evaporation equilibrium is an $\mathrm{n}$-shaped profile of water distribution [12]. The rising damp always acts vertically upwards in the construction. The equilibrium between capillarity and surface evaporation is schematically shown in Fig. 3 .

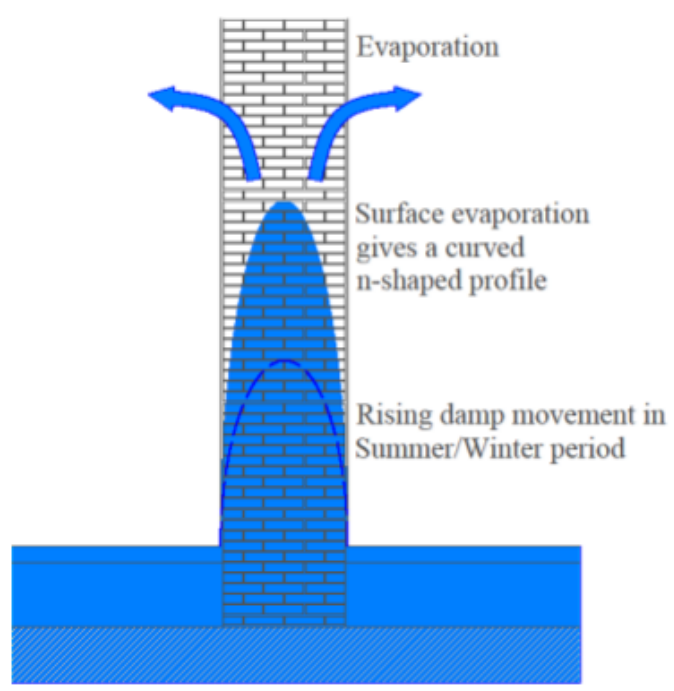

Fig. 3. Schematic diagram of a brick wall showing the equilibrium between capillary rise and evaporation

The influence of the wall thickness has already been analyzed, and as expected the thickness of the wall increases the level achieved by the moisture [1].

\subsection{Effects of soluble salts crystallization}

Groundwater contains soluble salts of which the most significant are sodium chloride, nitrate and sodium sulphate [2]. When rising damp occurs, these hygroscopic salts pass with the water up the wall and are left behind when the water evaporates. Salt crystallization cycles cause pressure inside porous materials which lead to disruptive effects such as pulverization, crumbling, blistering and flaking [13, 14]. Over many years of active rising dampness, large quantities of these salts accumulate within the masonry and decorative surface, most becoming concentrated. Both chlorides, nitrates and sulphates are usually hygroscopic, (i.e. they can absorb moisture from the surrounding environment) and, in general, the greater the amount of salts the greater the absorption of moisture, especially under humid conditions. Even though rising dampness may have been controlled by the insertion of a remedial damp-proof course these salts alone can cause the wall and any contaminated decorations to remain damp [15]. This process leads in a period of time leads to destruction of the building material. The current state of the buildings constructive walls are shown in Fig. 4. The intervention concepts basis is to prevent the rising damp as lower as possible above the basement floor.

In situ monitoring was performed in order to designate the damaged segments in the construction walls as shown on the elevation in Fig. 5. Saturated zones of the wall where the mortar and decoration is no longer present are coloured in black.

\subsection{Laboratory testing - Investigating the quality of ma- sonry units}

Masonry units quality had to be tested for the assessment of the constructions state and the deterioration caused by the salt crystalisation and moisture [16]. In order to determine the quality of masonry units built in the construction, six bricks were 

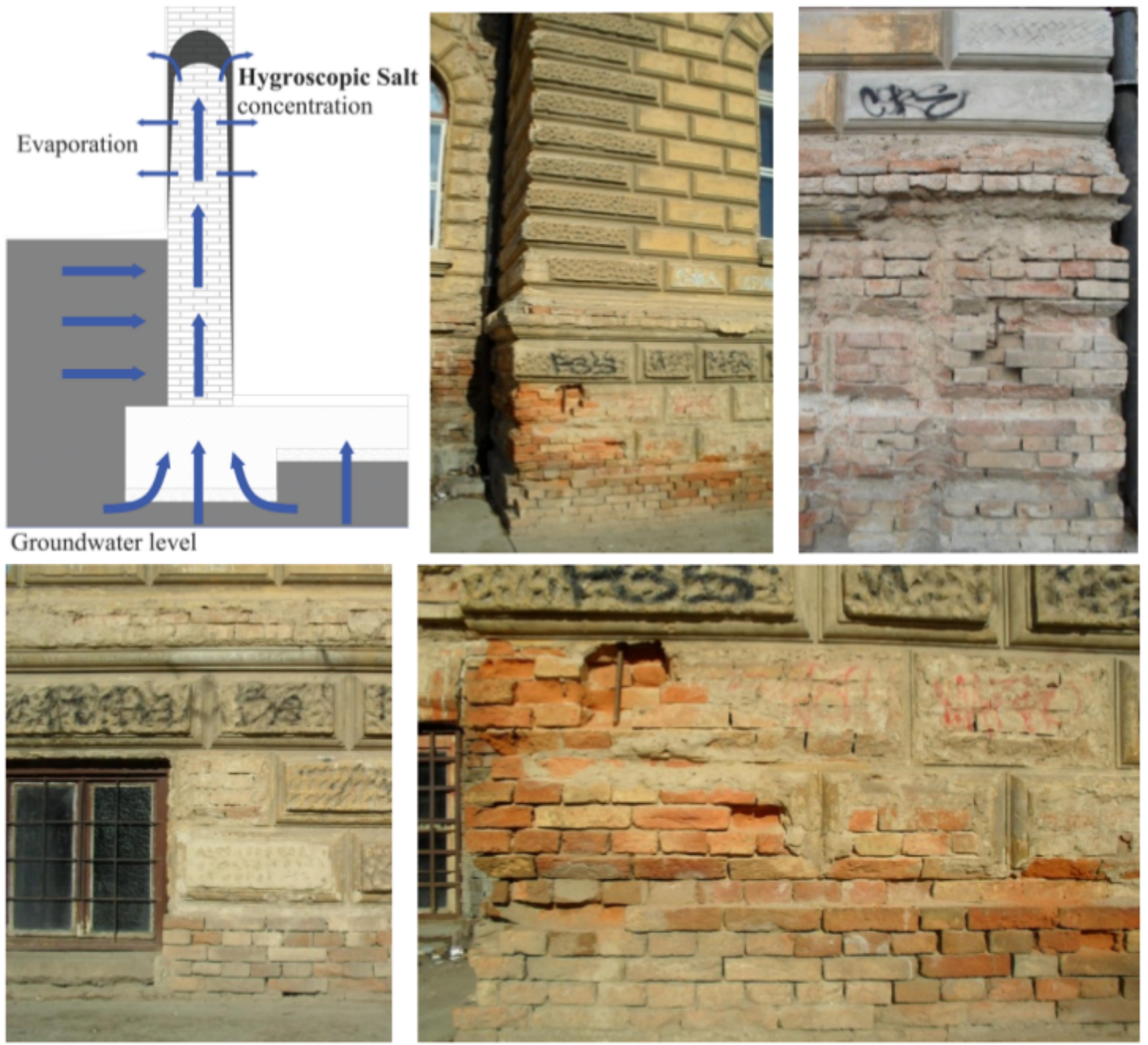

Fig. 4. Vertical rising damp in the analyzed constructive wall (upper left), current state of the constructive walls (photos)

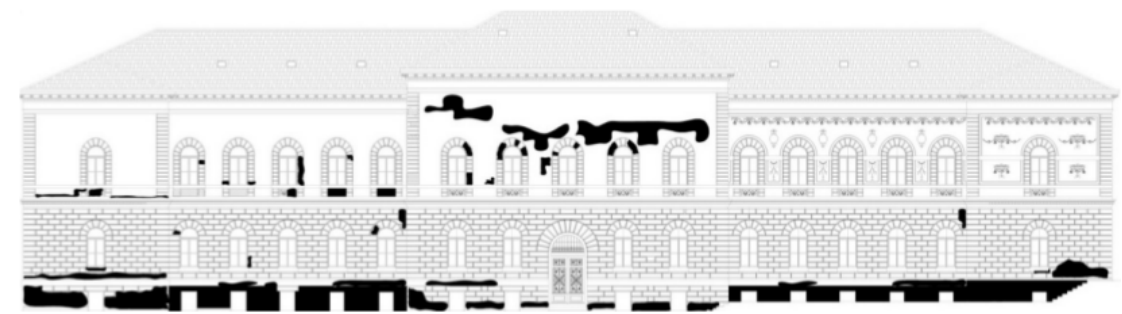

Fig. 5. Damaged segments due to the rising damp process 
taken for laboratory investigation. The bricks were taken from walls in the basement on $-1.5 \mathrm{~m},-2.0 \mathrm{~m}$ and $-2.5 \mathrm{~m}$ from the ground surface and first floor on the height $+0.4 \mathrm{~m}$ (two bricks) and $+0.8 \mathrm{~m}$ from ground surface.

With visual examination of the samples it is determined that old brick format was used. The measures are $29 \times 14 \times 6.5 \mathrm{~cm}$. The analyzed bricks have uneven surfaces with partial damages and remained mortar, as shown in Fig. 6 .

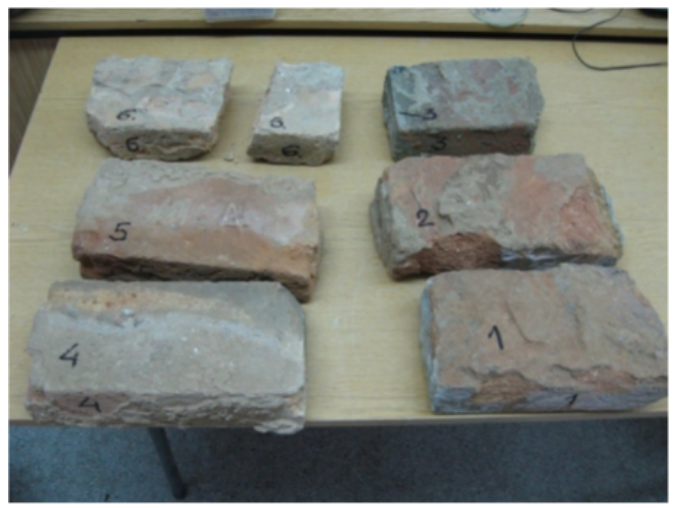

Fig. 6. Samples of bricks in laboratory

The testing of physical and mechanical properties of the bricks was performed according to the standard SRPS B.D8 . 011:2002 which consists of:

- Checking measures

- Determining natural moisture of bricks in built-in condition, density and maximum water absorption

- Testing compressive strength

\subsubsection{Checking measures}

The measured dimensions of the bricks are shown in Table 2 in the first three columns (some of them were partially destroyed).

\subsubsection{Determining natural moisture of bricks, density and} water absorption of bricks

Natural moisture of bricks in built-in condition is determined after drying the samples into dry-kiln until constant mass. The average and minimum value of moisture is $21.2 \%$ and $18.5 \%$ for the bricks from the basement, while $8.3 \%$ and $4.7 \%$ for the bricks from the first floor.

The pre-dried density is determined through the Eq. (4):

$$
\gamma=\frac{m_{d}}{V}\left[\mathrm{~kg} / \mathrm{m}^{3}\right]
$$

$m_{d} \quad$ mass of the unit in dry conditions $[\mathrm{kg}]$

$V \quad$ volume $\left[\mathrm{m}^{3}\right]$

The measured mass and calculated density of the bricks is shown above, in Table 2. The results vary between $1310 \mathrm{~kg} / \mathrm{m}^{3}$ and $1667 \mathrm{~kg} / \mathrm{m}^{3}$.
In order to measure water absorption, the analyzed samples (in dry condition) were put into water and remained there until fully saturated. Water absorption is calculated by the Eq. (5):

$$
\omega=\frac{m_{1}-m_{2}}{m_{2}} \cdot 100[\%]
$$

$m_{1} \quad$ final mass of brick after saturation [kg]

$m_{2} \quad$ initial mass of the brick in dry condition $[\mathrm{kg}]$

The duration of the absorption investigation was five days and the obtained results are presented above, in the last column of Table 2 for all masonry units.

\subsubsection{Testing compressive strength}

Testing was performed on three samples, each with two joint bricks. The samples for testing compressive strength are shown in Fig. 7. The obtained results are shown in Table 3. The compressive strength is calculated by the Eq. (6) below:

$$
f_{b}=\frac{F}{A}\left[N / \mathrm{mm}^{2}\right]
$$

$F \quad$ breaking load [N]

A surface $\left[\mathrm{mm}^{2}\right]$

After the carried out examination it is concluded that the compressive strength of the brick is $5.76 \mathrm{~N} / \mathrm{mm}^{2}$ decreased in the basement on level $-2.5 \mathrm{~m}$ according to the first floor on level $+0.8 \mathrm{~m}$. The strength decrement is critical from the constructional aspect, since moisture and salt crystallization destructs the materials structure and weakens the resistance for higher loads.

\section{Selection of optimal remedial method}

\subsection{Criteria of selection}

Modern engineering practice offers various damp handling methods. The procedure of appropriate damp handling is demonstrated in the following. The most widespread methods for rising damp handling in masonry construction are: [1, 3, 17]

- chemical method (injection),

- electric method,

- continuous construction heating method,

- ventilation method,

- horizontal wall-cutting method.

The criteria of optimization was formed according to the:

- effectiveness,

- duration of the handling procedure,

- economic aspects. 
Tab. 2. Properties of the bricks

\begin{tabular}{|c|c|c|c|c|c|c|}
\hline Bricks & Length [mm] & Width [mm] & Height [mm] & Mass [kg] & Density $\left[\mathrm{kg} / \mathrm{m}^{3}\right]$ & Water absorption [\%] \\
\hline 1 (basement $-2.5 \mathrm{~m}$ ) & 218 & 146 & 76 & 4.032 & 1667 & 22.9 \\
\hline 2 (basement $-2.0 \mathrm{~m}$ ) & 307 & 149 & 75 & 5.530 & 1612 & 21.7 \\
\hline 3 (basement $-1.5 \mathrm{~m}$ ) & 253 & 152 & 70 & 4.234 & 1573 & 20.3 \\
\hline 4 (first floor $+0.4 \mathrm{~m}$ ) & 303 & 152 & 81 & 5.148 & 1380 & 18.8 \\
\hline 5 (first floor $+0.4 \mathrm{~m}$ ) & 293 & 149 & 74 & 4.452 & 1378 & 18.7 \\
\hline 6 (first floor $+0.8 \mathrm{~m}$ ) & 310 & 152 & 71 & 4.382 & 1310 & 17.9 \\
\hline
\end{tabular}
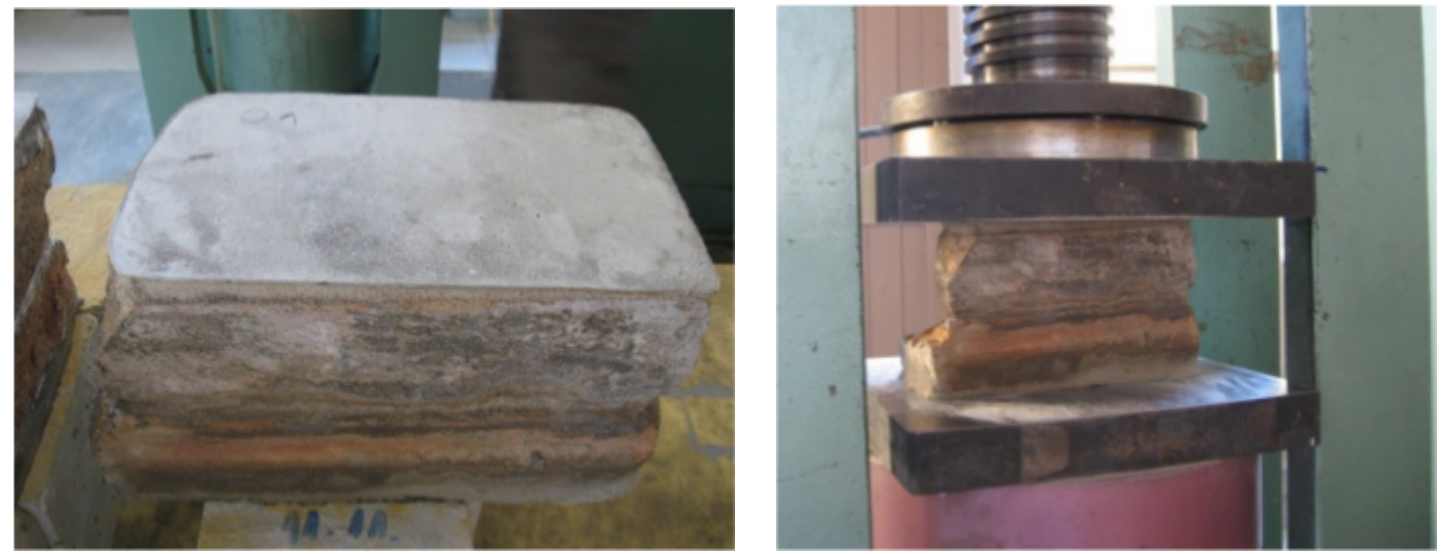

Fig. 7. Testing compressive strength

Tab. 3. Compressive strength of bricks

\begin{tabular}{cccc}
\hline Bricks & $A\left[\mathrm{~cm}^{2}\right]$ & $F[\mathrm{kN}]$ & $f_{p}\left[\mathrm{~N} / \mathrm{mm}^{2}\right]$ \\
\hline O1 & 320.35 & 230 & 7.18 \\
O2 & 392.16 & 360 & 9.18 \\
O3 & 456.02 & 590 & 12.94 \\
\hline
\end{tabular}

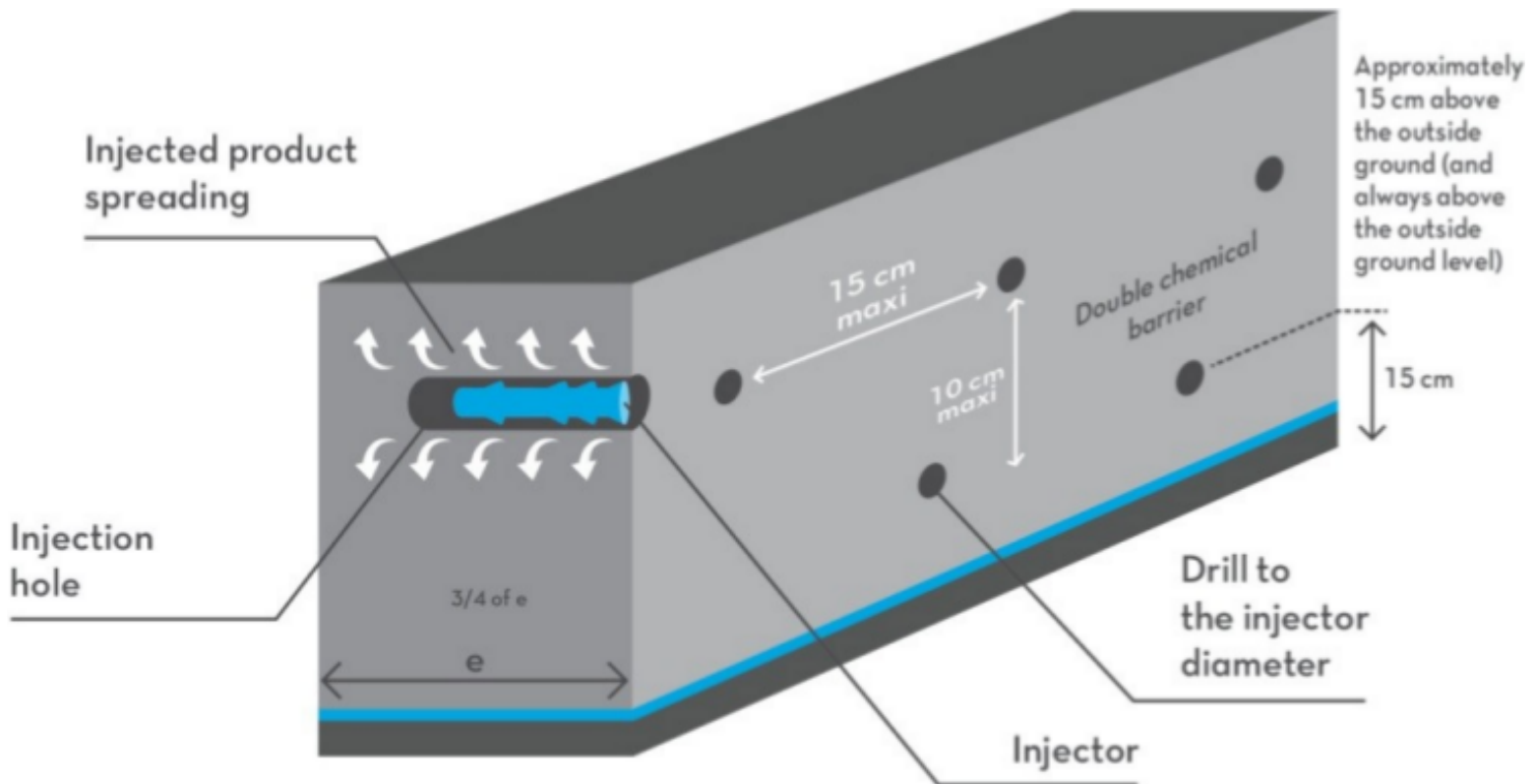

Fig. 8. Chemical method - injection 


\subsection{Discussion}

The effectiveness of the rising damp handling depends on the percentual elimination of moisture in the construction. The optimal efficiency would result in absolute dryness of the wall.

The efficiency of the chemical method (injection) depends on how much the materials from outside can reach the voids, and how effectively the right reactions are generated by the injection materials. The injection method is proven to be one of the most wide spread methods in engineering practice. With the use of this technique both masonry and concrete constructions can be treated effectively. In our case numerous holes have to be drilled in order to insert the injection mass which can result in damage of the walls structure, since the masonry units have already decreased compressive strength, as investigated. Considering the construction type and situation of the analyzed building all walls are available for handling from both sides. The chemical method in this case would be reasonable only, if one side of the damaged wall would be reachable, Fig. 8

The electric method is questionable, since the electric procedures result in transfer of moisture to another position in the wall due to ion migrations generated by electric potential. In this case the moisture would not be eliminated.

The continuous construction heating method changes the temperature conditions of the structure which changes the diffusion condition as well [6]. The perforations within the structure are calculated in order to determine the number and the depth of the holes. A heating installation system needs to be connected with the walls which utilize electricity, while the heating cables are needed to be changed in a period of time. When we consider the effectiveness of this system the result is that moisture can be stopped from further rising, yet is not eliminated fully from the construction.

The ventilation method consists of ventilating the base of the walls either through a natural ventilation process or by installing a hygro-regulated mechanical device, Fig. 9] [4]. The ventilation technique consists of a piping system (perforated tube $20 \times 20 \mathrm{~cm}$ ) and has to be placed on either one side or both sides of the treated walls. The system requires expenses in application due to its complexity. Since the analyzed buildings function in the basement is reserved for laboratories the channels would have to be inserted below the basement floor. This would require cutting of the basement floor slab minimum $30 \mathrm{~cm}$ from the wall, raising the expenses. A second barrier would appear due to the groundwater level. On the examined territory groundwater level varies in a wide range. The risk of saturating the channels can lead to system failure. Considering system efficiency the obtained results show that an optimal water content reduction in a $100 \mathrm{~cm}$ thick wall is $15.6 \%$. This specific result was obtained for the material Pedra de Anca. Considering various wall thicknesses (from $20 \mathrm{~cm}$ to $100 \mathrm{~cm}$ ) and material types the moisture content decrease varies from $30 \%$ to $15.6 \%$ [11].

Considering the above mentioned five methods the horizon-

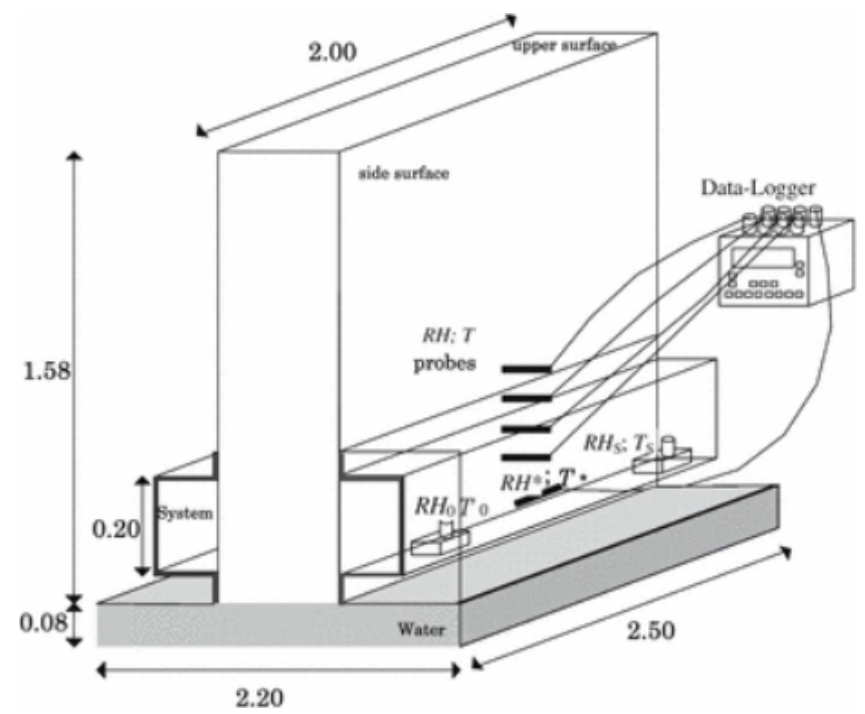

Fig. 9. Ventilation method [18]

tal wall-cutting technique eliminates $100 \%$ of rising damp, since all horizontal surfaces of the treated walls are cut through as low as possible from the ground or fundaments. The waterproofing material and mortar are inserted through the process of cutting. The vertical upward movement of water is eliminated. The following method is adequate for masonry construction of thick walls, as in case of the analyzed building in the paper, since cement-mortar is the only connector of the masonry units without any wall-reinforcement. However, if a building has reinforced concrete walls, than this method should not be performed, since the cutting of reinforcement bars and homogeneous concrete structure can bring to instability.

Evaluating the duration of the handling for the chemical (injection) -, continuous heating-, ventilation methods require a longer period for application due to the number of phase in the handling process. For the chemical (injection) method and the heating method perforations have to be drilled while the handling process begins afterwards. The ventilation process requires a very complex procedure for inserting the channels at the base of the walls. Regardless to the mentioned methods the horizontal wall-cutting technique in this case is appropriate from the aspect of the handling duration, since the cutting and the plate inserting are performed at the same time, without prolonging the process.

The aim is to fully protect the building from rising damp which leads to the criteria of eliminating the techniques which in our case would not offer full protection. Hence, the economic evaluation is demonstrated for two methods:

- chemical method (injection),

- horizontal wall-cutting method.

Both methods are effectively used for prevention of the rising damp in architectural heritage. Table 4 shows a proportional comparison of prices per technique. The proportional prices of the handling techniques for the two methods are presented for 
a single $\mathrm{m}^{2}$ and for the whole buildings horizontal wall surface. The prices of the techniques were compared in Euros from March 2013 and the following proportion of the prices per $\mathrm{m}^{2}$ was conducted: the chemical-injection method requires $25 \%$ more investments per $\mathrm{m}^{2}$, due to its more complex and durable damp handling technique. The proportional investment has been calculated according to the horizontal surfaces of the walls on the basement floor plan, as shown in Fig. 10][4].

The total evaluation and the selection of the optimal rising damp handling are demonstrated in Table 5. The methods which fit the requirements of the analyzed building receive a point in each category formed according to the criteria of optimization.

The output of the evaluation is the horizontal wall-cutting method as an optimal rising damp handling method for the analyzed masonry construction. In this case the effectiveness, duration of the handling procedure and the economic aspects fit the requirements.

\section{Rising damp handling process}

5.1 In-situ monitoring and proposal for rising damp handling

The current state of the building is show in the section, Fig. 11. Moisture is marked with blue lines on the inner and outer surface of the walls and basement floor. Salt concentration in the walls is marked with gray color. As shown the concentration of soluble salts reach the height of one floor and are concentrated in the connection zone of the constructive walls and slab. Since the damage caused by salt crystallization destructs the constructive material these segments of the walls are critical due to linear loads from the slab.

The proposal is to prevent further decay and deterioration in the masonry structure with the selected optimal rising damp handling. Waterproofing has to cut off all the vertical directions of the upward movement of groundwater. The solution has to detach the basement floor and walls from the building. Horizontal waterproofing has to be inserted covering the surface of the basement floor, and as low as possible in the walls above the basement floor.

\subsection{Phases of rising damp handling}

The handling method consists of three phases, as shown in Fig. 12. First of all, in Phase I, the vertical rising damp has to be cut off with horizontal wall-cutting technology and waterproofing panels have to be inserted below the whole surface of the wall. After having secured all walls from the rising damp, in Phase II, basement floor-waterproofing and vertical wallwaterproofing has to be performed. Finally, Phase III refers to the finishing work of the façade and reconstruction of the modular decoration according to source documentation.

\subsection{Phase I}

According to the selected optimal handling method for this specific study, horizontal wall-cutting technology (HIO-
Technology) will be used in the first phase of the rising damp handling [17]. A complete horizontal wall cut with this technology does not affect the stability of the construction. Damp walls are cut with ultra-rapid diamond cutting tools without causing vibration in the structure. HIO-MasterRail is a type of insulation, unique waterproofing with adaptations to high altitude cuts in the wall. Special waterproofing material panels have ribs which carry the load of the upper parts of the building, without any deformation.

An important segment of the HIO-Technology is the injection mass that connects the rail with the upper and lower surface of the cut. The injected mass completely fills the entire cut and the rail profiles. Madeon polymer basis has an excellent adhesion with the rail and creates an unbreakable connection between the wall and the new joint.

The process of wall-cutting with the HIO-Technology is demonstrated and explained in the following. Firstly the damp mortar has to be removed from the walls where the cutting is planned. Depending from the height of the rising damp the façade mortar has to be removed from all areas which are damaged, as shown in Fig. 13. Holes must be drilled through the constructive masonry structure for insertion of the ultra-speed steel-diamond cutter-cables, Fig. 14. The height of the drilling is adjusted. Afterwards the laying of cutter-cable has to be performed through the hole, as shown in Fig. 15. Fig. 16 demonstrates the plan of the cutting technique and machinery.

It is very important to mention that the whole surface of the wall has to be cut off, so the waterproofing panels can be inserted beneath the whole wall surface, achieving full prevention of moisture transfer. Fig. 17 displays the process of cutting. Fig. 18 shows the preparation of waterproofing panels, cutting the HIO-MasterRail panels to appropriate dimension. The horizontal cut has to be cleaned from the dust generated throughout the cutting process so the special adhesion mass can be injected and the HIO-MasterRail ribbed panels pushed into the wall cut, as shown in Fig. 19. When the process has been performed the result of the treated rising damp is shown in Fig. 20. After adequate waterproofing the façade finishing can be restored, Fig.21.

\subsection{Phase II}

The second phase refers to the basement floor- and vertical wall-waterproofing. The previous floor covering layers have to be removed for further construction. Construction details are shown below, in Fig. 22. When the previous covering is removed a concrete correction layer needs to be inserted to provide a plane layer for the waterproofing membrane.

The overlap of the two different waterproofing materials is described in detail A. For achieving long lasting waterproofing the connection has to be constructed with precision. Sika ${ }^{\circledR}$ products are utilized for the handling method [19]. The Sikamembrane ${ }^{\circledR}$ has to be set vertically to the same height where the HIO-MasterRail ${ }^{\circledR}$ is situated, overlapping it. The brick above the rail has to be removed partially, in our case $7 \mathrm{~cm}$ minimum, 
Tab. 4. Economic evaluation of the two damp handling technologies

\begin{tabular}{cccc}
\hline Damp handling technique & $\begin{array}{c}\text { Proportional price in } \\
€ / \mathrm{m}^{2}\end{array}$ & $\begin{array}{c}\sum \text { Proportional price in } \\
€ / \mathrm{m}^{2}\end{array}$ & Investment ratio \% \\
\hline Horizontal wall-cutting & 1.00 & 367.85 & 100 \\
Chemical - Injection & 1.25 & 459.81 & 125 \\
\hline
\end{tabular}

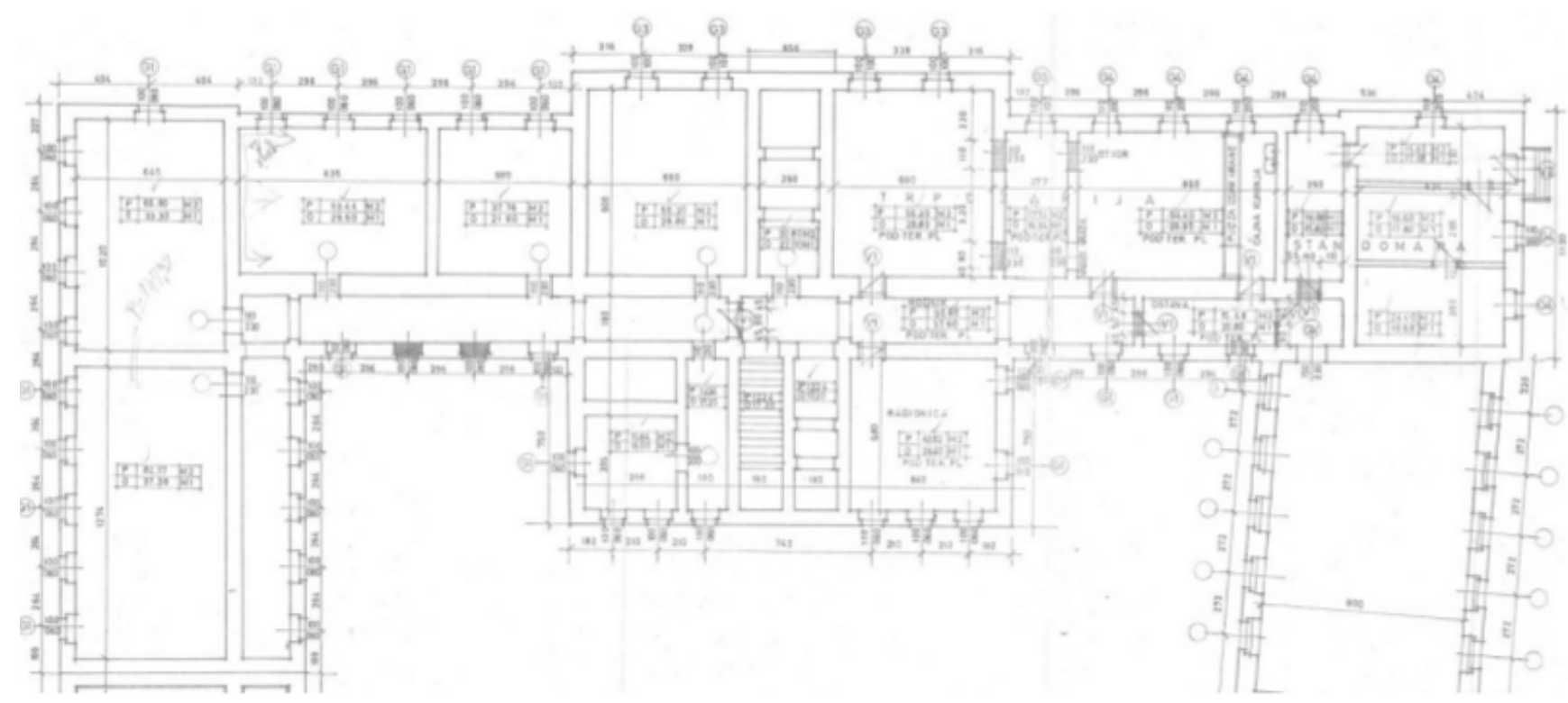

Fig. 10. Basement floor plan

Tab. 5. Evaluation of the method according to the criteria of optimization

\begin{tabular}{|c|c|c|c|c|}
\hline $\begin{array}{c}\text { Type of handling } \\
\text { method }\end{array}$ & Effectiveness & $\begin{array}{c}\text { Duration of the } \\
\text { handling procedure }\end{array}$ & Economic aspects & Sum \\
\hline $\begin{array}{l}\text { Chemical method } \\
\text { (injection) }\end{array}$ & 1 & 0 & 0 & 1 \\
\hline $\begin{array}{l}\text { Electric method } \\
\text { Continuous }\end{array}$ & 0 & 0 & 0 & 0 \\
\hline $\begin{array}{c}\text { construction } \\
\text { heating method }\end{array}$ & 1 & 0 & 0 & 1 \\
\hline Ventilation method & 0 & 0 & 0 & 0 \\
\hline $\begin{array}{c}\text { Horizontal } \\
\text { wall-cutting method }\end{array}$ & 1 & 1 & 1 & 3 \\
\hline
\end{tabular}

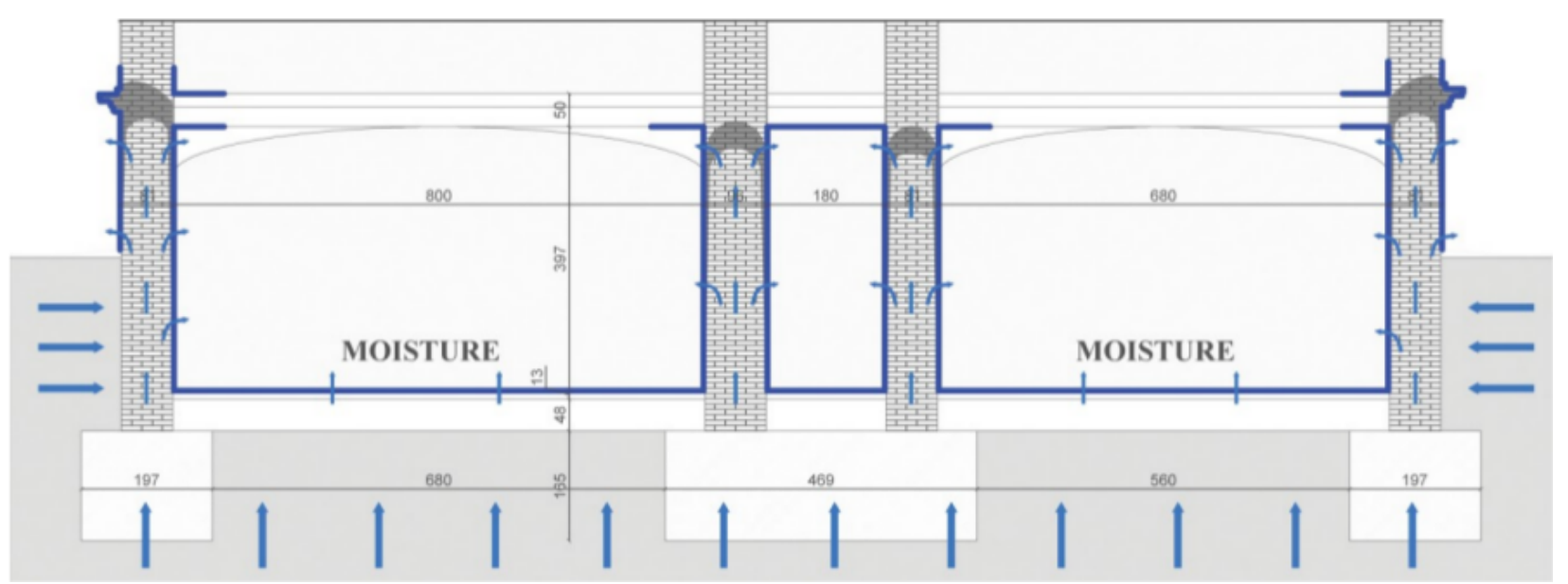

Fig. 11. Current state without waterproofing 


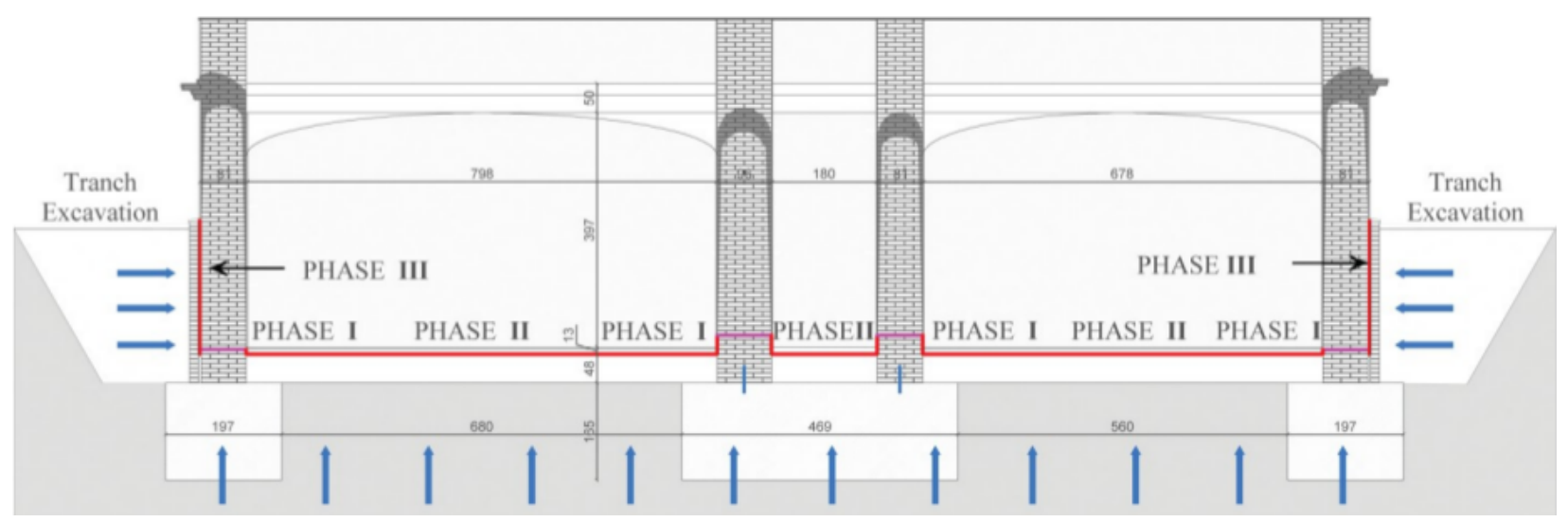

Fig. 12. Phases of waterproofing: Phase I - Horizontal wall-cutting technol- work ogy, Phase II - Waterproofing of walls and basement floor, Phase III - Finishing

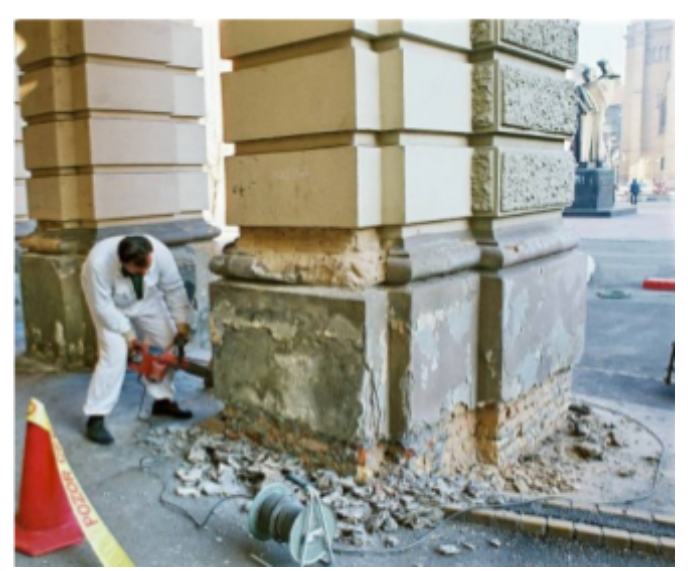

Fig. 13. Removing the mortar

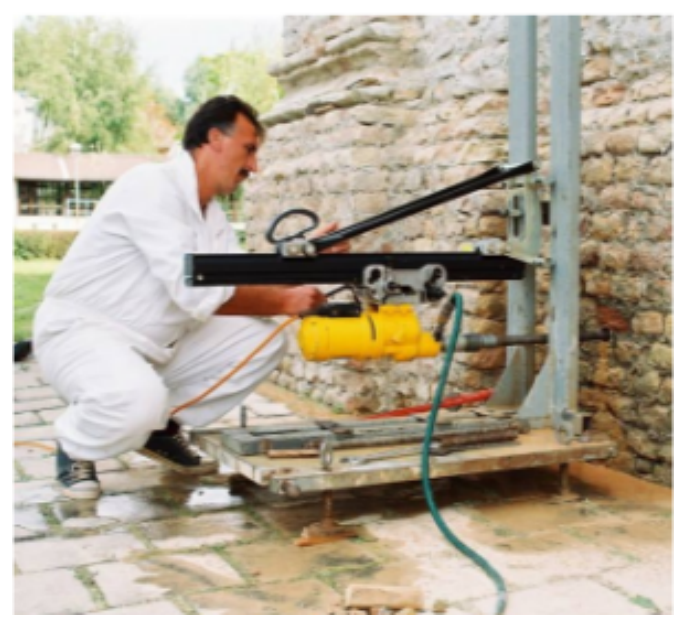

Fig. 14. Drilling holes

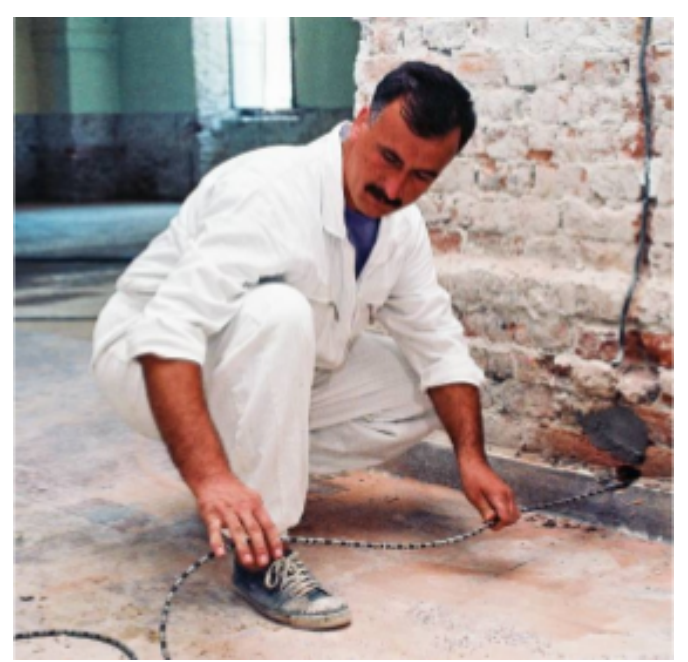

Fig. 15. Laying the cutter-cable

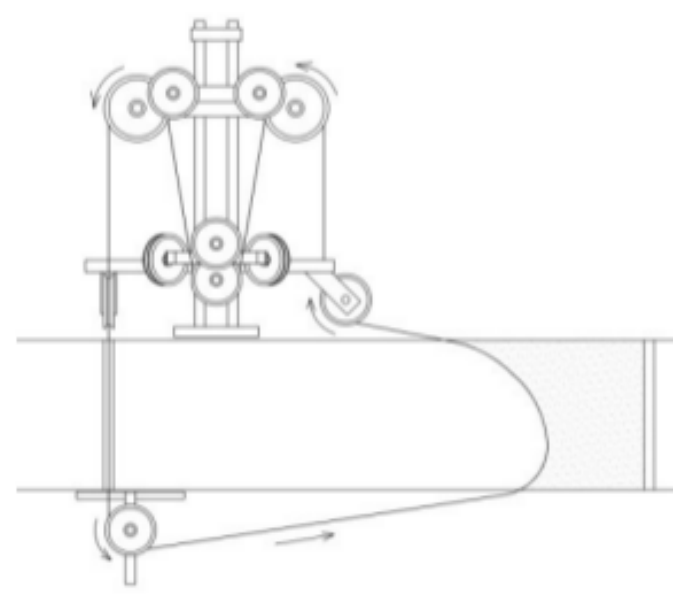

Fig. 16. Machinery 


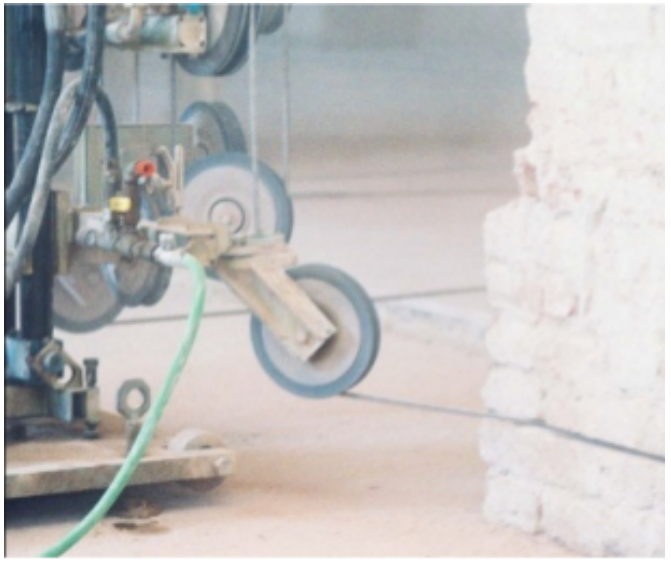

Fig. 17. Process of cutting

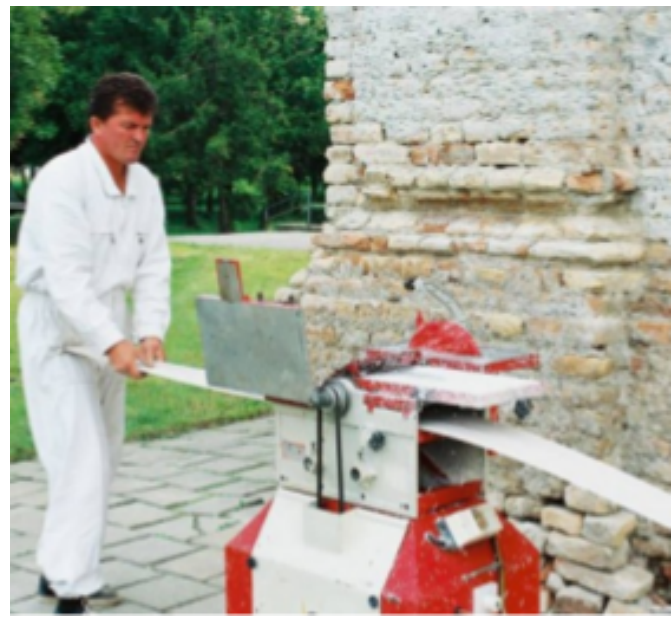

Fig. 18. HIO-MasterRail preparation

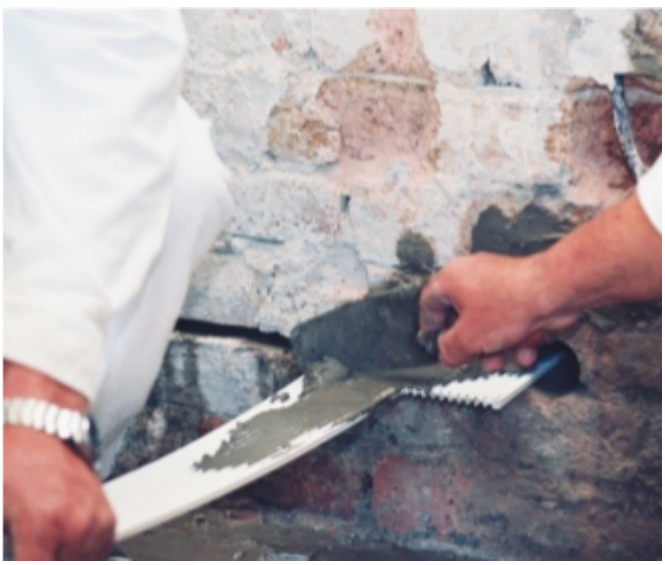

Fig. 19. Injecting the adhesion mass and Rail positioning so the folding of the membrane could be preformed. The wall surface where the membrane is has to be inflicted with waterproofing mortar for preventive case and security of the connection in detail A. Afterwards a $7 \mathrm{~cm}$ thick concrete waterproofing protection layer with light reinforcement has to be constructed, in order to stabilize the connection. The floor covering layers include thermal insulation, slip sheet, cement-mortar composite layer and ceramic tile finishing.

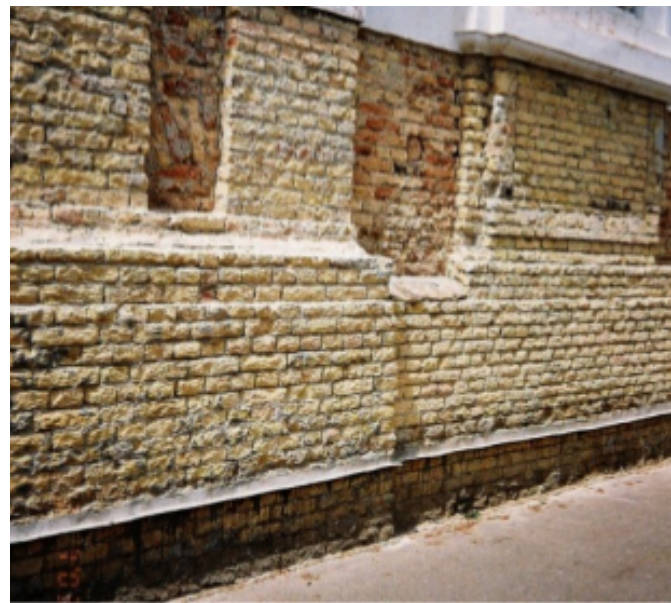

Fig. 20. Finished rising damp handling

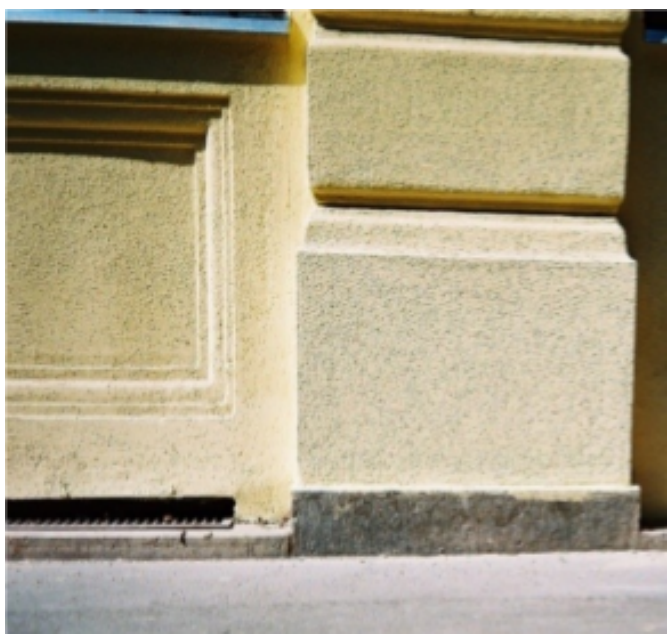

Fig. 21. Restored decoration

1 Ceramic tile, $6 \mathrm{~mm}$

2 Glue

3 Cement-mortar composite layer, $40 \mathrm{~mm}$

4 Slip sheet

5 Thermal insulation, rigid boards, $40 \mathrm{~mm}$

6 Waterproofing $-\mathrm{Sika}^{\circledR}$ membrane

7 Concrete correction layer, $20 \mathrm{~mm}$

8 Basement floor - existing construction

9 Inside wall-finishing, mortar, $15 \mathrm{~mm}$

10 Reinforced concrete waterproofing-protection layer, $70 \mathrm{~mm}$ 
11 HIO-MasterRail ${ }^{\circledR}$

12 Waterproofing - Sika ${ }^{\circledR}$ membrane

13 Sika $^{\circledR}$ waterproofing mortar, $15 \mathrm{~mm}$

14 Basement masonry wall construction, $110 \mathrm{~cm}$

The outer wall and basement floor waterproofing connection detail is shown in Fig. 23 below. The overlap of the two different waterproofing materials has to be preformed the same as in the previous detail. The floor covering layers maintain the same in the whole basement. The layers for the outer wall have to provide waterproofing as well. The connection detail of the HIOMasterRail ${ }^{\circledR}$ and Sika-membrane ${ }^{\circledR}$ is shown below in detail B. Since no overlapping is included in this zone, the protection is achieved with waterproofing mortar.

1 Ceramic tile, $6 \mathrm{~mm}$

2 Glue

3 Cement-mortar composite layer, $40 \mathrm{~mm}$

4 Slip sheet

5 Thermal insulation, rigid boards, $40 \mathrm{~mm}$

6 Waterproofing - Sika ${ }^{\circledR}$ membrane

7 Concrete correction layer, $20 \mathrm{~mm}$

8 Basement floor - existing construction

9 Soil

10 Brick protection layer, $120 \mathrm{~mm}$

$11 \mathrm{Sika}^{\circledR}$ waterproofing mortar, $20 \mathrm{~mm}$

12 Waterproofing - Sika ${ }^{\circledR}$ membrane, $3 \mathrm{~mm}$

13 Mortar, $17 \mathrm{~mm}$

14 Basement masonry wall construction, $80 \mathrm{~cm}$

15 HIO-MasterRail ${ }^{\circledR}$

16 Concrete waterproofing-protection layer, $60 \mathrm{~mm}$

\subsection{Phase III}

The modular decoration on the façade has to be reconstructed according to source documentation. The decorative façade has to be reconstructed according to the architectural style. The decoration in the lower façade segment, reaching the height of $2 \mathrm{~m}$ has to be reconstructed according to the southern elevation in Fig. 24 [4]. The characteristic outline of the secession style is monumentality, which is achieved with simple geometrical forms. This representative effect is reached with repetitive modular design. The repetition and symmetry are coordinated with the façade architecture which is divided into segments where the fenestration division is different from segment to segment. The fields between the windows are filled with rectangles of different dimensions. A segment of the modular rectangular decoration is shown in Fig. 25 The reconstruction of the mortar decoration has to be performed by specialists in this field, following the exact forms and measures according to source documentation. The principle of this reconstruction is not considered in the paper.

\section{Conclusion}

Masonry construction of architectural heritage is always disposed to damp effect and on the area of Vojvodina Province due to soil structure, groundwater level and lack of waterproofing techniques in the construction period of the buildings. To prevent further deterioration and destruction of $19^{\text {th }}$ century masonry structures the primary requirement is to prevent further vertical upward movement of moisture in the construction, and offer a long lasting solution.

Analysis proofs that active rising dampness accumulates large quantities of soluble salts within the masonry which causes destruction and decay in the structure of the material. Laboratory testing determined the decrement in material quality of bricks from the analyzed building due to salt crystallization and forced upon rapid intervention.

According to the proposal, construction type and the masonry units condition a selection has been preformed among the most disseminated damp handling methods in engineering practice. For the optimization of the handling method the criteria was formed according to the:

- effectiveness,

- duration of the handling procedure, and

- economic aspects.

If the proposal, construction type and the construction material would be different, the same critical method would offer other output results.

The selected optimal handling method is described in three phases, and demonstrated with the combination of waterproofing products. The paper explains a detailed methodical approach to the optimization of rising damp prevention which can be performed for buildings of similar architectural and constructive characteristics. 


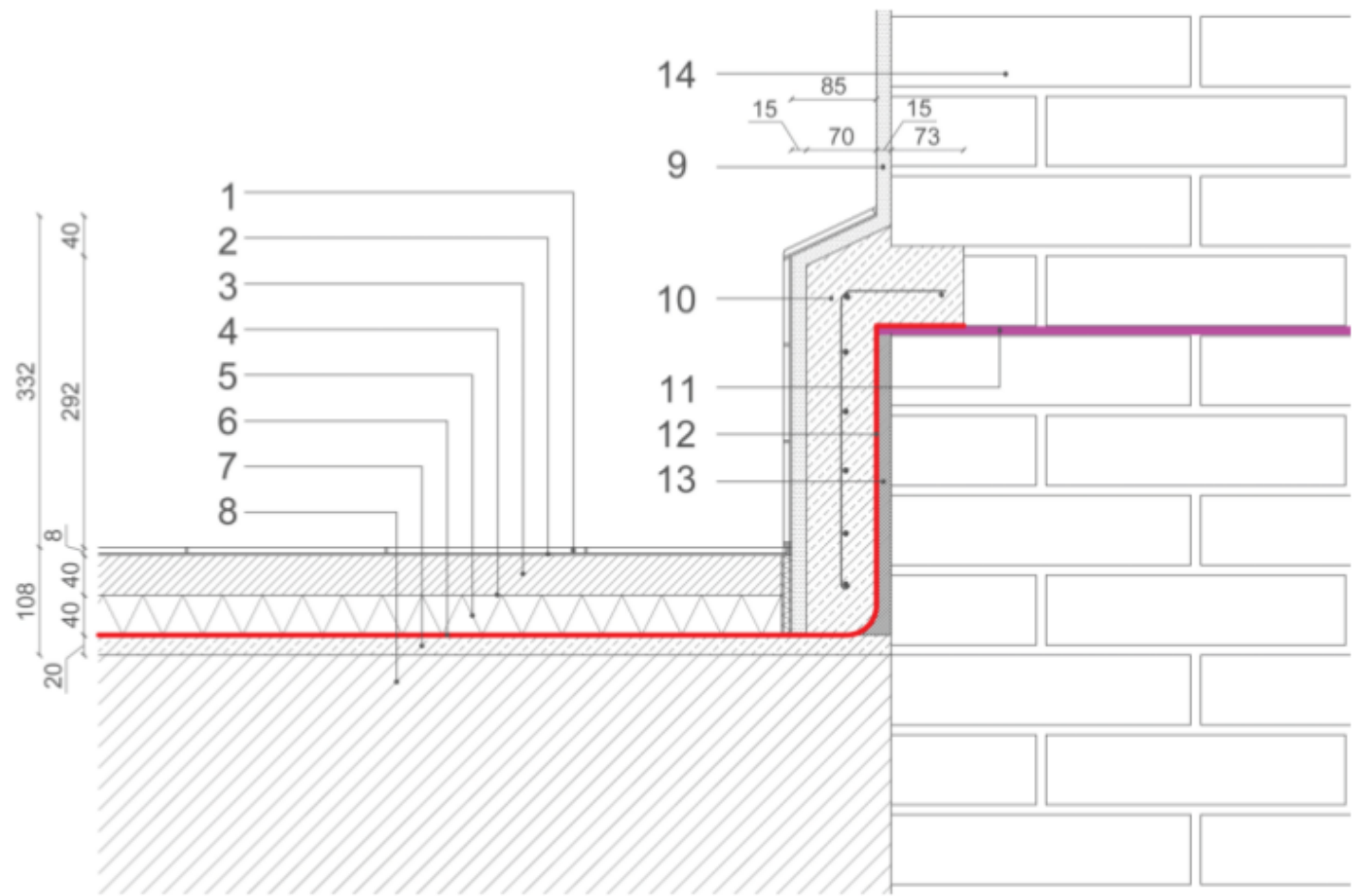

Fig. 22. Detail of inner wall and basement floor waterproofing

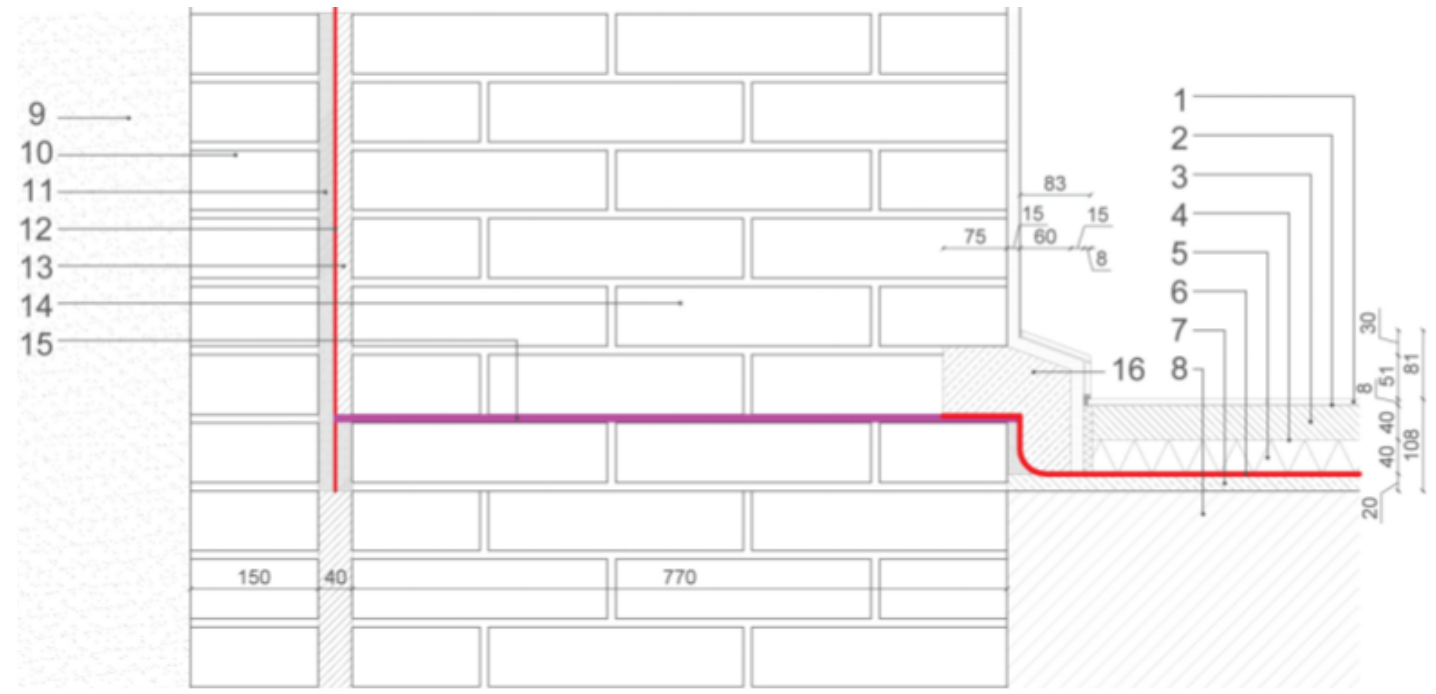

Fig. 23. Detail of outer wall and basement floor waterproofing

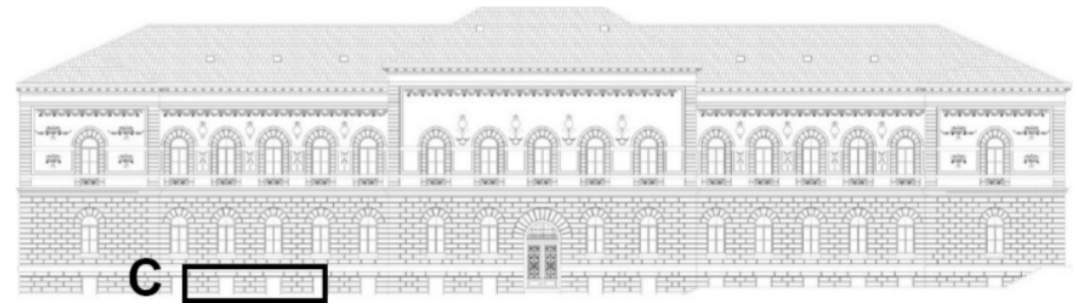

Fig. 24. Southern elevation

\begin{tabular}{|c||c||c||c||c||c||c||c|||||}
\hline & $130 / 30$ & $80 / 30$ & $80 / 30$ & $130 / 30$ & $80 / 30$ & $80 / 30$ & $130 / 30$ \\
\hline
\end{tabular}

Fig. 25. Segment of the modular rectangular decoration, detail C from Fig.24 


\section{References}

1 Torres I, de Freitas V, The influence of the thickness of the walls and their properties on the handling of rising damp in historic buildings, Construction and Building Materials, 24, (2010), 1331-1339, DOI 10.1016/j.conbuildmat.2010.01.004

2 Gentilini C, Franzoni E, Bandini S, Nobile L, Effect of salt crystallization on the shear behavior of masonry walls: An experimental study, Construction and Building Materials, 37, (2012), 181-189, DOI 10.1016/j.conbuildmat.2012.07.086

3 Várfalvi J, Thermodynamic “Damp Proofing” of old buildings, Periodica Polytechnica Architecture, 38(2), (2007), 67-71, DOI 10.3311/pp.ar.20072.04

4 Technical documentation of building, High School of Civil and Electrical Engineering, Institute for Cultural Heritage and Preservation; Zrenjanin, Serbia, 2007.

5 Karavida V, Zrenjanin - Graditeljska bastina - The architectural heritage, Knjizara Teatar; Zrenjanin, 2002.

6 Kadijevic A, Aesthetics of architectural Academicism (19th and 20th Century), Graoevinska Knjiga; Belgrade, 2005.

7 Hoff W, Hall C, Rising damp: capillary rise dynamics in walls, Proceedings of the Royal Society A: Mathematical, Physical and Engineering Sciences, 463(2084), (2007), 1871-1884, DOI 10.1098/rspa.2007.1855

8 Raimondo $\mathbf{M}$, Predicting the initial rate of water absorption in clay bricks, Construction and Building Materials, 23, (2009), 2623-2630, DOI 10.1016/j.conbuilmat.2009.01.009

9 Maksimovic M, Soil Mechanics Third edition, Graoevinska knjiga; Belgrade, 2005.

10 Karoglou M, Moropoulou A, Krokida M, Maroulis Z, A powerful simulator for moisture transfer in buildings, Building and Environment, 42, (2007), 902-912, DOI 10.1016/j.buildenv.2005.10.008

11 Watt D, Colston B, Investigating the effects of humidity and salt crystallization on medieval masonry, Building and Environment, 35, (2000), 737-749.

12 Risch E, Zhang Z, Rising damp in masonry walls and the importance of mortar properties, Construction and Building Materials, 24, (2010), 18151820, DOI 10.1016/j.conbuilmat.2010.04.024

13 Espinoza-Marzal R, Scherer G, Advances in understanding damage by salt crystallization, Accounts of Chemical Research, 43, (2010), 897-905, DOI 10.1021/ar9002224

14 Scherer G, Stress from crystallization of salt, Cement and Concrete Research, 34, (2004), 1613-1624, DOI 10.1016/j.cemconres.2003.12.034

15 Rising Damp (Salt Damp), Safeguard Europe Ltd.; Redkiln Close, Horsham, West Sussex, RH13 5QL, United Kingdom, 2011.

16 Fódi A, Effects influencing the compressive strength of a solid, fired clay brick, Periodica Polytechnica Civil Engineering, 55(2), (2011), 117-128, DOI 10.3311/pp.ci.2011-2.04

17 Horizontal wall-cutting technology, HIO-protection system Kft.; Budapest, Hungary, 2011, http://www.hio-technology.com

18 Guimaraes A, Delgado J, de Freitas V, Rising damp in building walls: the wall base ventilation system, Heat and Mass Transfer, 48(12), (2012), 2079-2085, DOI 10.1007/s00231-012-1053-3

19 Sika waterproofing solutions and products, Sika AG Company; Switzerland, 2012, http://www.sika.com 